\title{
Anionic Effect on the Acidic Corrosion of Aluminum and its Inhibition by Lupine Extract
}

\author{
B.A. Abd-El-Naby, ${ }^{a}$ O.A. Abdullatef, ${ }^{b, *}$ H.M. El-Kshlan, ${ }^{c}$ E. Khamis ${ }^{d}$ and \\ M.A. Abd-El-Fatah ${ }^{c}$ \\ ${ }^{a}$ Faculty of Science, Chem Dept, Alexandria University, P.O. Box 426, Alexandria 21321, Egypt \\ ${ }^{b}$ Pharos University, Faculty of Pharmacy, Kanal Elmahmodia Street, Smoha, Alexandria, Egypt \\ ${ }^{c}$ Faculty of Education, Alexandria University, Alexandria, Egypt \\ ${ }^{d}$ City of Scientific Research \& Technological Applications, New Borg El-Arab City, P.O. Box: 21934 \\ Alexandria, Egypt
}

Received 2 July 2015; accepted 2 August 2015

\begin{abstract}
Corrosion behavior of aluminum in $0.1 \mathrm{M} \mathrm{HCl}, 0.1 \mathrm{M} \mathrm{HClO}_{4}$ and $0.05 \mathrm{M} \mathrm{H}_{2} \mathrm{SO}_{4}$ solutions was studied using potentiodynamic polarization and electrochemical impedance spectroscopy (EIS) techniques. The results showed that the rate of corrosion of aluminum was arranged in the order: $\mathrm{HCl}>\mathrm{HClO}_{4}>\mathrm{H}_{2} \mathrm{SO}_{4}$. Lupine extract is an effective green inhibitor for the corrosion of aluminum in acidic solutions. The inhibition efficiency of the extract was found to increase with increasing the concentration of the extract. The obtained results showed that the lupine extract is effective in the order $\mathrm{HClO}_{4}>\mathrm{HCl}>\mathrm{H}_{2} \mathrm{SO}_{4}$. Theoretical fitting of the corrosion data to the Kinetic-thermodynamic model was tested to clarify the nature of adsorption.
\end{abstract}

Keywords: Corrosion, acidic, aluminum, lupine, adsorption.

\section{Introduction}

Aluminum is a reactive metal [1]; aluminium and aluminium alloys are extensively used in industry in a variety of aggressive aqueous environments covering a wide range of $\mathrm{pH}$. Aluminum is usually protected by a thin oxide film, whose solubility is negligible in neutral solutions ( $\mathrm{pH}$ interval 4.0-8.5) at room temperature provided the solution does not contain activating anions, whereas heavy corrosion is observed both in acidic and alkaline media [2]. Anodizing in sulfuric acid solution can produce the protective oxide layer [3].

\footnotetext{
*Corresponding author. E-mail address: ossama_abdullatef@yahoo.com.
} 
The presence of chloride ions in the solution has some disadvantages like producing pitting in oxide film [4]. One of the most common methods to protect metals against acid corrosion is the use of inhibitors which reduce the corrosion rate of metals and alloys in contact with aggressive environment. Organic inhibitors are often used to protect metallic materials against corrosion in acidic as well as in alkaline media. It is generally agreed that adsorption of organic molecules at the $\mathrm{Al}$ - solution interface can lead to corrosion inhibition either by physically blocking the surface active sites or by retarding the electrochemical reactions [5]. The inhibition effect of some amino acids (alanine, leucine, valine, proline, methionine, and tryptophan) towards the corrosion of aluminum in $1 \mathrm{M}$ $\mathrm{HCl}+1 \mathrm{M} \mathrm{H}_{2} \mathrm{SO}_{4}$ solution was investigated using weight loss measurement, linear polarization and SEM techniques [6]. The inhibition of three ethoxylated fatty acids of different molecular weights on the corrosion of aluminum in both $1.0 \mathrm{M} \mathrm{HCl}$ and $1.0 \mathrm{M} \mathrm{H}_{2} \mathrm{SO}_{4}$ solutions has been studied at different temperatures $\left(25-55^{\circ} \mathrm{C}\right)$ by means of weight loss and potentiodynamic polarization techniques. The inhibition efficiency for the three fatty acids increases with the increase in the inhibitors concentration but decreases with increasing temperature [7]. Most of the corrosion inhibitors are synthetic chemicals which are expensive and very hazardous to environment [8]. There has been increasing search for green corrosion inhibitors; inhibitors in this class are those that are environmentally friendly and are gotten from natural products such as plant extracts. This area of research is of much importance because in addition to being inexpensive, they are readily available and renewable sources of materials. Plant products are organic in nature and some of their constituents including tannins, organic and amino acids, alkaloids and pigments are known to exhibit inhibiting action [9]. Therefore, it is desirable to source for environmentally safe inhibitors, which have been found to generally exhibit good inhibition efficiencies. Pectin, which is a natural polymer, is a successful corrosion inhibitor on the surface of aluminum metal in acidic media [10]. The inhibition effect of Jasminum Nudiflorum Lindl Leaves extract (JNLLE) on the corrosion of aluminum in 1.0 $\mathrm{M} \mathrm{HCl}$ solution was studied by weight loss, potentiodynamic polarization, electrochemical impedance spectroscopy and scanning electron microscopy (SEM) methods [11].

The aim of this work is to investigate the anionic effect on the acidic corrosion of aluminum and its inhibition by lupine extract.

\section{Experimental}

\section{Electrochemical tests}

Electrochemical impedance and polarization curve measurements were achieved using an ACM 604 Instrument. The frequency range for EIS measurements was $0.01 \leq \mathrm{f} \leq 3 \times 10^{4} \mathrm{~Hz}$ with an applied potential signal amplitude of $10 \mathrm{mV}$ around the rest potential. Polarization curve measurements were carried out at the scan rate $20 \mathrm{mV} / \mathrm{min}$. The data were obtained in a three electrode mode; graphite rod and saturated calomel electrode were used as counter and reference electrodes. The specimens used for constructing the working electrode were aluminum rods 
that had the following chemical composition (wt \%): Al 99.687; Mn 0.001; Zn 0.001; Ni 0.001; Ti 0.003; Fe 0.171; Si 0.135; Cu 0.001. The aluminum samples were fixed in poly tetrafluoro ethylene (PTFE) rods by an epoxy resin in such a way that only one surface was left uncovered. The exposed area $\left(0.786 \mathrm{~cm}^{2}\right)$ was mechanically polished with a series of emery papers of variable grades; the samples were then washed thoroughly with distilled water followed by A.R. ethanol and finally with distilled water, just before insertion in the cell. Measurements were done at $30^{\circ} \mathrm{C}$.

\section{Plant and preparation of the plant extract}

These items were discussed in our recent work [12].

\section{Preparation of the test solutions}

Prior each experiment, 1.0 $\mathrm{M} \mathrm{HClO}_{4}, 1.0 \mathrm{M} \mathrm{HCl}$ or $0.5 \mathrm{M} \mathrm{H}_{2} \mathrm{SO}_{4}$ are added to an appropriate volume of the stock solution of the lupine extract and double distilled water to obtain solutions of $0.1 \mathrm{M} \mathrm{HClO}_{4}, 0.1 \mathrm{M} \mathrm{HCl}$ and $0.05 \mathrm{M} \mathrm{H}_{2} \mathrm{SO}_{4}$ and the required concentration of the extract.

\section{Results and discussion}

\section{Corrosion of aluminum in the aqueous acidic solutions}

Fig. 1 represents the potentiodynamic polarization curves for aluminum in the three studied mineral acids at $30{ }^{\circ} \mathrm{C}$. The polarization curves show Tafel behavior. In presence of $\mathrm{HCl}$, the active region is followed by break down potential $\mathrm{E}_{\mathrm{b}}$; this behavior has been previously reported by several authors [13, 14] and has been explained on the basis of the pitting corrosion of aluminum. The potentiodynamic polarization parameters for aluminum in different mineral acids at $30{ }^{\circ} \mathrm{C}$ are presented in Table 1.

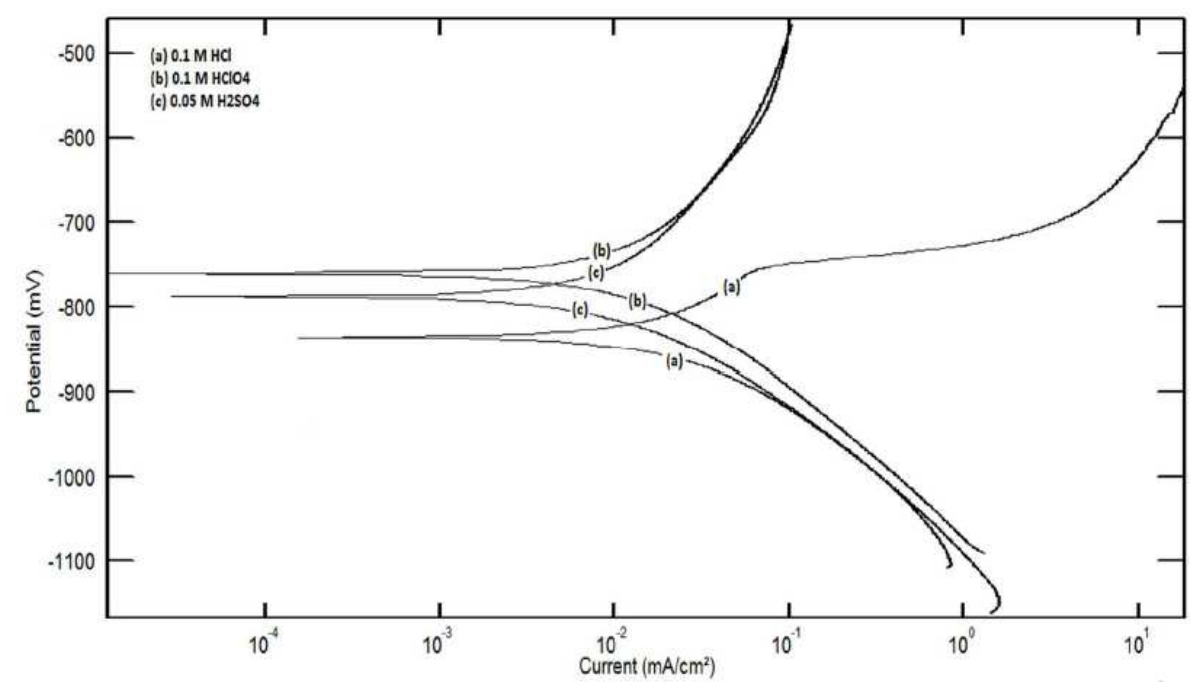

Figure 1. Potentiodynamic polarization curves for aluminum in $0.1 \mathrm{M} \mathrm{HCl}, 0.1 \mathrm{M}$ $\mathrm{HClO}_{4}$ and $0.05 \mathrm{M} \mathrm{H}_{2} \mathrm{SO}_{4}$ solutions at $30{ }^{\circ} \mathrm{C}$. 
Fig. 2 represents the Nyquist plots for aluminum in $0.1 \mathrm{M} \mathrm{HCl}, 0.1 \mathrm{M} \mathrm{HClO}_{4}$ and $0.05 \mathrm{M} \mathrm{H}_{2} \mathrm{SO}_{4}$. These plots indicate that the impedance response consisted of depressed capacitive semicircle. The experimental data were analyzed by fitting the data to the equivalent circuit model represented in Fig. 3, using Zsimpwin program. This equivalent circuit includes the solution resistance $\mathrm{R}_{\mathrm{s}}$ shorted by the capacitor $C_{d l}$ which is placed in parallel to the charge transfer resistance $R_{c t}$. The data obtained are presented in Table 2.

Table 1. Values of the polarization parameters for aluminum in $0.1 \mathrm{M} \mathrm{HCl}, 0.1 \mathrm{M}$ $\mathrm{HClO}_{4}$ and $0.05 \mathrm{M} \mathrm{H}_{2} \mathrm{SO}_{4}$ solutions at $30{ }^{\circ} \mathrm{C}$.

\begin{tabular}{||c||c||c||c||c||}
\hline \hline Type of acid & $\begin{array}{c}\mathbf{E}_{\text {corr }} \\
(\mathbf{m V})\end{array}$ & $\begin{array}{c}\boldsymbol{\beta}_{\mathbf{a}} \\
\mathbf{m V} / \mathbf{d e c a d e}\end{array}$ & $\begin{array}{c}\boldsymbol{\beta}_{\mathbf{c}} \\
\mathbf{m V} / \mathbf{d e c a d e}\end{array}$ & $\begin{array}{c}\mathbf{i}_{\text {corr }} \\
\left(\mathbf{m A . c m} \mathbf{- n}^{-2}\right.\end{array}$ \\
\hline \hline $\mathbf{H C l}(\mathbf{0 . 1} \mathbf{M})$ & -792.7 & 136.8 & 203.6 & 0.0339 \\
\hline $\mathrm{HClO}_{4}(\mathbf{0 . 1 M})$ & -774.0 & 375.8 & 201.8 & 0.0229 \\
\hline $\mathrm{H}_{2} \mathrm{SO}_{4}(\mathbf{0 . 0 5 M})$ & -769.9 & 298.0 & 173.5 & 0.0155 \\
\hline \hline
\end{tabular}

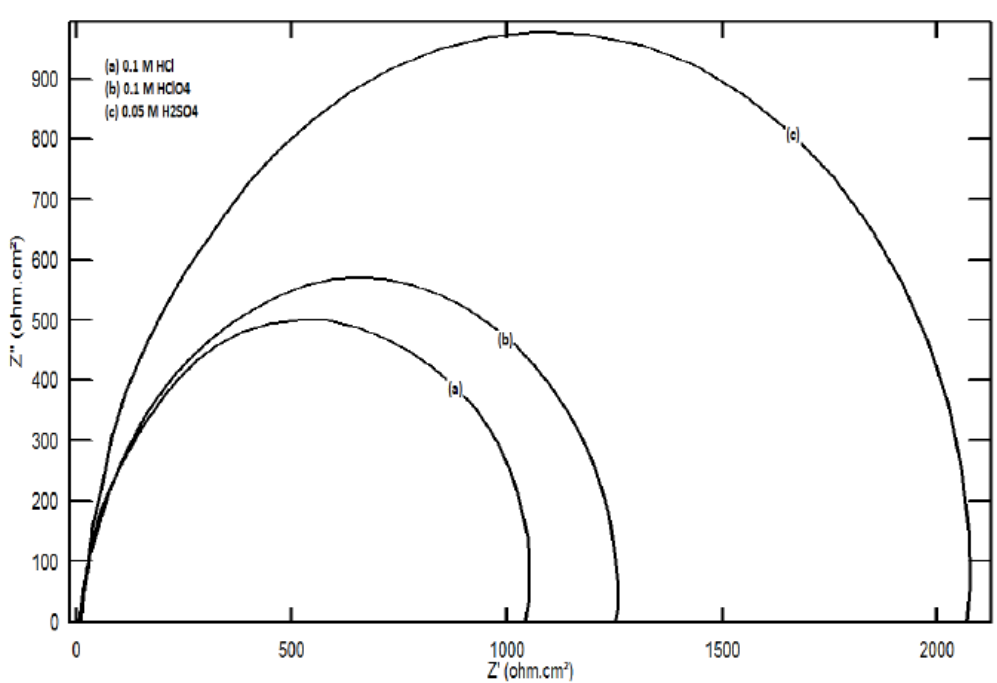

Figure 2. Nyquist plots for aluminum in $0.1 \mathrm{M} \mathrm{HCl}, 0.1 \mathrm{M} \mathrm{HClO}_{4}$ and $0.05 \mathrm{M} \mathrm{H}_{2} \mathrm{SO}_{4}$ solutions at $30^{\circ} \mathrm{C}$.

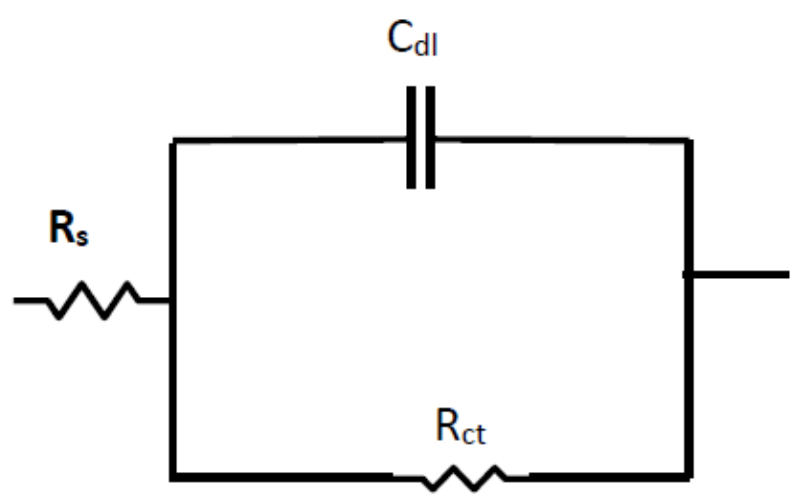

Figure 3. The equivalent circuit model.

The results showed that $\mathrm{R}_{\mathrm{ct}}$ is arranged in the order: $\mathrm{HCl}<\mathrm{HClO}_{4}<\mathrm{H}_{2} \mathrm{SO}_{4}$; these results are in agreement with the results obtained from the potentiodynamic 
polarization technique and also with the results obtained previously [15] using the gasometry technique. It has been reported that the addition of $\mathrm{Cl}^{-}$ions increases the anodic dissolution rate of aluminum either by incorporation of the $\mathrm{Cl}^{-}$ion into the oxide film, by which additional charge carriers are generated [16], or by the participation of $\mathrm{Cl}^{-}$ions in the metal dissolution reaction $[17,18]$. In our previous work [19], the action of $\mathrm{Cl}^{-}$ions as an accelerator has been explained on the basis of ionic incorporation into a surface film which depends upon ionic size. Consequently $\mathrm{Cl}^{-}$ions, by their small size, can be easily incorporated. However, the bulky size of $\mathrm{ClO}_{4}{ }^{-}$and $\mathrm{SO}_{4}{ }^{2-}$ anions would not allow their incorporation and consequently little effect would be expected on the corrosion behavior of aluminum metal. The double negative charge on $\mathrm{SO}_{4}{ }^{2-}$ anion makes it weaker incorporated and consequently makes it the least to affect the corrosion behavior of aluminum metal. In other words, the higher values of $\mathrm{R}_{\mathrm{ct}}$ in the case of sulfate ions can be explained on the basis of the formation of a binuclear surface complex [15].

Table 2. The values of the impedance parameters for aluminum in $0.1 \mathrm{M} \mathrm{HCl}, 0.1 \mathrm{M}$ $\mathrm{HClO}_{4}$ and $0.05 \mathrm{M} \mathrm{H}_{2} \mathrm{SO}_{4}$ solutions at $30{ }^{\circ} \mathrm{C}$.

\begin{tabular}{|c|c|c|c|}
\hline Type of acid & $\underset{\text { Ohm.cm }}{\mathbf{R}_{\mathrm{s}}}$ & $\begin{array}{c}\mathrm{C}_{\mathrm{dl}} \\
\mu \mathrm{F} . \mathrm{cm}^{-1}\end{array}$ & $\underset{\text { Ohm.cm }}{\mathbf{R}_{\mathrm{ct}}}$ \\
\hline $\begin{array}{ll}\text { HCl } & (0.1 \mathrm{M})\end{array}$ & 07.57 & 13.53 & 1006 \\
\hline $\mathrm{HClO}_{4}(0.1 \mathrm{M})$ & 11.26 & 09.96 & 1186 \\
\hline $\begin{array}{ll}\mathrm{H}_{2} \mathrm{SO}_{4} & (0.05 \mathrm{M})\end{array}$ & 12.10 & 10.05 & 1967 \\
\hline
\end{tabular}

\section{Corrosion of aluminum in acidic solutions containing lupine}

Fig. 4 represents Nyquist plots for aluminum in $0.1 \mathrm{M} \mathrm{HClO}_{4}$ solution in the absence and presence of different concentrations of Lupine extract. The figure manifested only one depressed capacitive semicircle. The diameter of the semicircle increases with increasing the extract concentration. The percentage inhibition was calculated from impedance measurements using the relation:

$$
\% \text { inh. }=\left[\left(\mathrm{R}_{\mathrm{ct}}-\mathrm{R}_{\mathrm{ct} 0}\right) / \mathrm{R}_{\mathrm{ct}}\right] \times 100
$$

where $R_{c t 0}$ and $R_{c t}$ are the charge transfer resistances in the absence and presence of different concentrations of the extract. Similar results obtained for aluminum in $0.1 \mathrm{M} \mathrm{HCl}$ and $0.05 \mathrm{M} \mathrm{H}_{2} \mathrm{SO}_{4}$ solutions in absence and presence of lupine extract.

The values of the electrochemical parameters obtained from EIS for aluminum in $0.1 \mathrm{M} \mathrm{HCl}, 0.1 \mathrm{M} \mathrm{HClO}_{4}$ and $0.05 \mathrm{M} \mathrm{H}_{2} \mathrm{SO}_{4}$ solutions containing different lupine extract concentrations and the inhibition efficiency are given in Table 3. It is clearly seen that the presence of lupine extract enhances the values of $R_{c t}$ and reduces the $C_{d l}$ values. The decrease in $C_{d l}$ is due to the adsorption of the extract to form an adherent film on the metal surface [20]. 


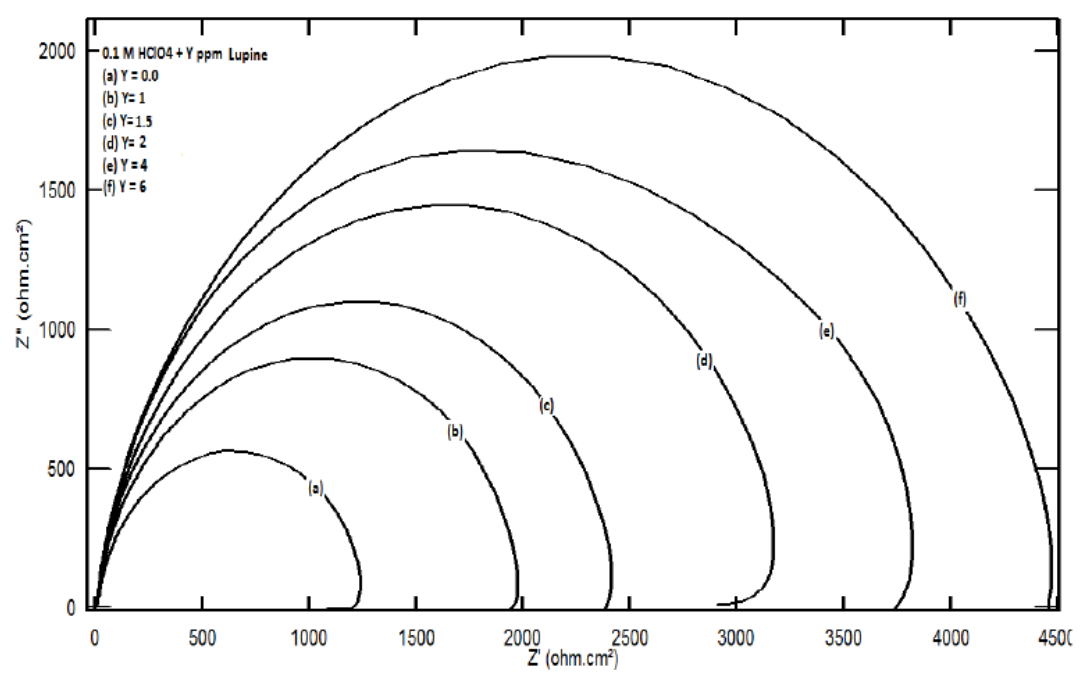

Figure 4. Nyquist plots for aluminum in $0.1 \mathrm{M} \mathrm{HClO}_{4}$ in presence of different concentrations of lupine extract at $30^{\circ} \mathrm{C}$.

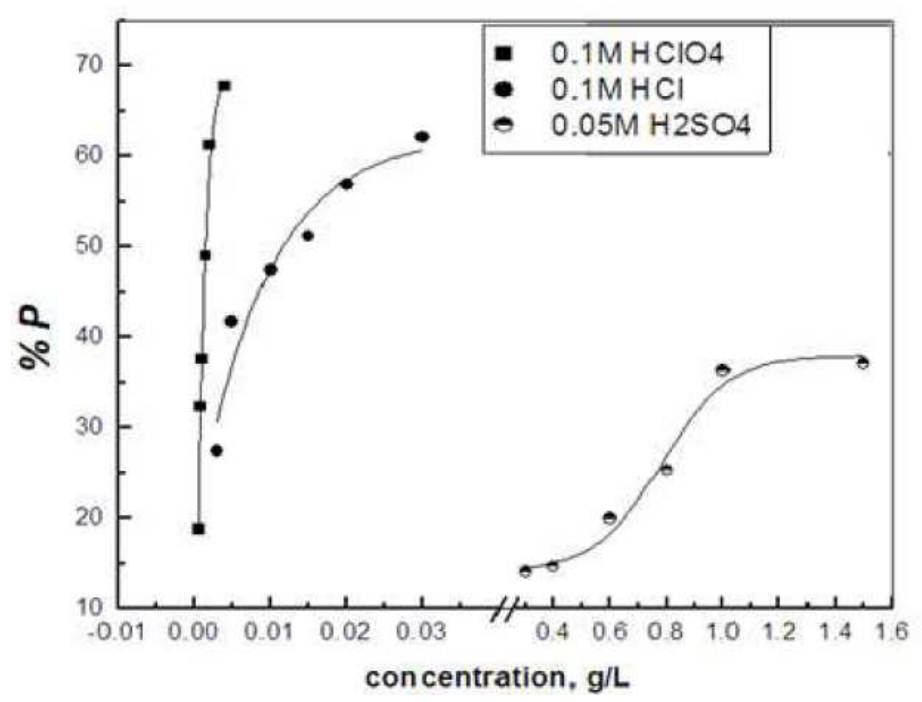

Figure 5. Variation of the percentage inhibition of aluminium in $0.1 \mathrm{M} \mathrm{HCl}, 0.1 \mathrm{M} \mathrm{HClO}_{4}$ and $0.05 \mathrm{M} \mathrm{H}_{2} \mathrm{SO}_{4}$ solutions with concentration of lupine extract.

The variation of the percentage inhibition with concentration of lupine extract is shown in Fig. 5. These curves represent adsorption isotherms that are characterized by first sharp rising part followed by another gradual rising part indicating formation of a monolayer adsorbed film on the aluminum surface [21]. The figure also confirms the fact that the inhibition action of lupine extract for aluminum corrosion in acid medium is in the order: $\mathrm{HClO}_{4}>\mathrm{HCl}>\mathrm{H}_{2} \mathrm{SO}_{4}$.

\section{Application of the kinetic-thermodynamic model}

The Kinetic-Thermodynamic model [22] is given by:

$$
\log [\theta /(1-\theta)]=\log \mathrm{K}^{\prime}+\mathrm{y} \log \mathrm{C}
$$

where $\mathrm{y}$ is the number of inhibitor molecules occupying one active site. The binding constant $\mathrm{K}$ is given by 


$$
\mathrm{K}=\mathrm{K}^{\prime}(1 / \mathrm{y}) .
$$

Table 3. Impedance parameters for aluminum in $0.1 \mathrm{M} \mathrm{HCl}, 0.1 \mathrm{M} \mathrm{HClO}_{4}$ and $0.05 \mathrm{M}$ $\mathrm{H}_{2} \mathrm{SO}_{4}$ in presence of different concentrations of lupine extract at $30^{\circ} \mathrm{C}$.

\begin{tabular}{|c|c|c|c|c|}
\hline \multicolumn{5}{|c|}{ 0.1 M HCl } \\
\hline $\begin{array}{l}\text { Conc. } \\
\text { (ppm) }\end{array}$ & $\begin{array}{c}\mathbf{R}_{\mathrm{s}} \\
\text { Ohm.cm }\end{array}$ & $\begin{array}{c}C \\
\mu \mathrm{F} . \mathrm{cm}^{-1}\end{array}$ & $\begin{array}{c}\mathbf{R}_{\mathrm{ct}} \\
\text { Ohm.cm }\end{array}$ & $\% \mathbf{P}$ \\
\hline 0.0 & 7.57 & 13.53 & 1006 & \\
\hline 2 & 7.79 & 9.15 & 1225 & 17.9 \\
\hline 3 & 7.24 & 11.18 & 1387 & 27.5 \\
\hline 5 & 6.71 & 10.46 & 1728 & 41.8 \\
\hline 10 & 6.66 & 10.12 & 1913 & 47.4 \\
\hline 15 & 6.62 & 9.95 & 2060 & 51.2 \\
\hline 20 & 6.82 & 9.77 & 2333 & 56.9 \\
\hline 30 & 6.90 & 9.40 & 2657 & 62.1 \\
\hline 50 & 6.84 & 9.71 & 2966 & 66.1 \\
\hline 70 & 7.08 & 9.53 & 3259 & 69.2 \\
\hline 80 & 6.91 & 8.94 & 3572 & 71.9 \\
\hline 100 & 6.92 & 9.48 & 3514 & 71.4 \\
\hline \multicolumn{5}{|c|}{$0.1 \mathrm{M} \mathrm{HClO}_{4}$} \\
\hline 0.0 & 11.31 & 9.84 & 1186 & \\
\hline 0.5 & 8.39 & 9.65 & 1461 & 18.8 \\
\hline 0.75 & 7.20 & 9.37 & 1755 & 32.4 \\
\hline 1 & 7.50 & 8.94 & 1903 & 37.7 \\
\hline 1.5 & 7.64 & 9.18 & 2330 & 49.1 \\
\hline 2 & 11.01 & 9.04 & 3066 & 61.3 \\
\hline 4 & 9.03 & 8.27 & 3684 & 67.8 \\
\hline 6 & 9.36 & 8.48 & 4266 & 72.2 \\
\hline 7 & 8.44 & 8.47 & 4606 & 74.3 \\
\hline 8 & 13.78 & 8.34 & 5075 & 76.6 \\
\hline \multicolumn{5}{|c|}{$0.05 \mathrm{M} \mathrm{H}_{2} \mathrm{SO}_{4}$} \\
\hline 0.0 & 11.95 & 10.32 & 1983 & \\
\hline 300 & 12.94 & 9.243 & 2310 & 14.2 \\
\hline 400 & 14.23 & 9.925 & 2325 & 14.7 \\
\hline 600 & 12.06 & 9.724 & 2478 & 20.0 \\
\hline 800 & 16.64 & 7.146 & 2656 & 25.3 \\
\hline 1000 & 13.9 & 8.279 & 3115 & 36.3 \\
\hline
\end{tabular}


Fig. 6 shows the linear fitting of lupine results according to the KineticThermodynamic model. The parameters obtained from these figures are given in Table 4. It is clear that the number of active sites occupied by a single inhibitor molecule, $1 / y$ were nearly equal one in the presence of $\mathrm{ClO}_{4}^{-}$ions indicating that the inhibitor molecule occupied only one active site. But the values of $1 / y$ in case of $\mathrm{Cl}^{-}$and $\mathrm{SO}_{4}{ }^{2-}$ ions indicate that each inhibitor molecule occupies more than one active site on aluminum surface.

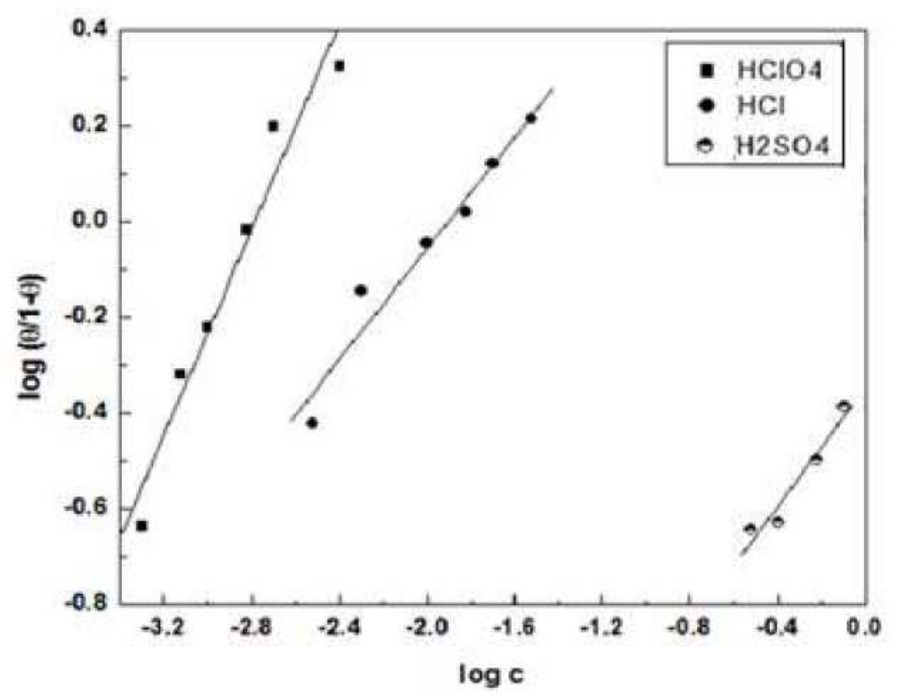

Figure 6. Application of the Kinetic-Thermodynamic model to the results of adsorption of lupine extract in $0.1 \mathrm{M} \mathrm{HCl}, 0.1 \mathrm{M} \mathrm{HClO}_{4}$ and $0.05 \mathrm{M} \mathrm{H}_{2} \mathrm{SO}_{4}$ solutions on aluminum surface.

Since the efficiency of a given inhibitor is essentially a function of the magnitude of its binding constant $\mathrm{K}$ [19], the increase in the values of $\mathrm{K}$ in the presence of $\mathrm{ClO}_{4}^{-}$ions indicates better and stronger interaction of the inhibitor molecules with the metal surface in presence of perchlorate ions. This behavior can be discussed on the basis of the low coordination ability of the perchlorate ion which tends to make the active sites of aluminum surface free and ready to adsorb the inhibitor molecules. However, the value of $\mathrm{K}$ is smaller in the case of $\mathrm{SO}_{4}{ }^{2-}$ anion which can be interpreted based on the fact that the $\mathrm{SO}_{4}{ }^{2-}$ anion is bulky and has two negative charges, and mainly coordinates with active sites of the aluminum surface; this makes it weaker to adsorb the inhibitor molecules.

Table 4. Linear fitting parameters of Lupine according to the Kinetic-Thermodynamic model for aluminum in $0.1 \mathrm{M} \mathrm{HCl}, 0.1 \mathrm{M} \mathrm{HClO}_{4}$ and $0.05 \mathrm{M} \mathrm{H}_{2} \mathrm{SO}_{4}$.

\begin{tabular}{|c|c|c|}
\hline \multirow{3}{*}{ Medium } & \multicolumn{2}{|c|}{ Model parameters } \\
\hline & \multicolumn{2}{|c|}{ Kinetic-Thermodynamic } \\
\hline & $1 / \mathbf{1}$ & $\mathbf{K}$ \\
\hline $\mathrm{HClO}_{4}$ & 0.93 & 613.3 \\
\hline $\mathrm{HCl}$ & 1.73 & 80.3 \\
\hline $\mathrm{H}_{2} \mathrm{SO}_{4}$ & 1.61 & 0.28 \\
\hline
\end{tabular}




\section{Conclusions}

The rate of corrosion of aluminum in aggressive mineral acid media was arranged in the order $\mathrm{HCl}>\mathrm{HClO}_{4}>\mathrm{H}_{2} \mathrm{SO}_{4}$. The $\mathrm{Cl}^{-}$ions increase the anodic dissolution rate of aluminum by their incorporation in the oxide film, however, the bulky size of $\mathrm{ClO}_{4}^{-}$and $\mathrm{SO}_{4}{ }^{2-}$ anions would not allow their incorporation. Also, the sulfate ion forms a binuclear surface complex with aluminum.

Lupine extract is effective for the acidic corrosion of aluminum in the order $\mathrm{HClO} 4>\mathrm{HCl}>\mathrm{H}_{2} \mathrm{SO}_{4}$.

The inhibitor molecules strongly interact with the metal surface in the presence of perchlorate ions due to the low coordination ability of the perchlorate ion; however, the sulfate ions coordinate with the metal surface makes it weaker to adsorb the inhibitor molecules.

\section{References}

1. Metikos-Hucovic M. J Appl Electrochem. 2002; 32:35.

2. Pourbaix M. Atlas of Electrochemical Equilibria in Aqueous Solutions. London: Pergamon Press; 1966.

3. Wernick S, Pinner R, Sheasby PG. The Surface Treatment of Aluminum and its Alloys. Teddington: ASN International Finishing Publications Ltd; 1987.

4. Beligiannis DS, Dimogerontakis $K$, Ninni Th, et al. Corros Sci. 2004;46:1765.

5. Hackerman N. Corrosion. 1962;18:332.

6. Ashassi-Sorkhabi H, Ghasemi Z, Seifzadeh D. Appl Surf Sci. 2005;249:408.

7. El-Sherbini EEF, Abd-El-Wahab SM, Deyab MA. Mater Chem Phys. 2003; 82:631.

8. Umoren SA. Desalination. 2009; 247:561.

9. Oguzie EE. Corros Sci. 2007; 49:1527.

10. Faresa MM, Maayta AK, Al-Qudah MM. Corros Sci. 2012;60:112.

11. Shuduan D, Xianghong Li. Corros Sci. 2012;64:253.

12. Abd-El-Naby BA, Abdullatef OA, El-Kshlan HM, et al. Port Electrochim Acta. 2015;33:1.

13. Khalil N, Mahgoub F, Abd-El-Nabey BA, et al. Corros Eng Sci Tech. 2003;38: 205.

14. Yadav PNS, Singh K, Wadhwani R. Corrosion. 1999;55:937.

15. El-Awady AA, Abd-El-Nabey BA, Aziz SG. J Chem Soc Faraday Trans. 1993;89:795 .

16. Lin LF, Chao CY, Macdownald DDJ. Appl Electrochem Soc. $1981 ; 18: 1194$.

17. Albert J, Kulandaina MA, Ganesan M, et al. J Appl Electrochem. 1989;19:547.

18. Pyun SIP, Lee EJ. Electrochim Acta. 1963:40.

19. Khalil N, Mahgoub F, Abd-El-Nabey BA, et al. Corros Eng Sci Techn. 2003;38,205. 
20. Musa AY, Kadhum AA, Mohamad H, et al. Current Appl Phys. 2012;12:325.

21. Abdel-Gaber AM, Abd-El-Nabey BA, Saadawy M. Corros Sci. 2009;51:1038.

22. El-Awady A, Abd El-Nabey BA, Aziz G. Electochem Soc. 1992;139:2149. 